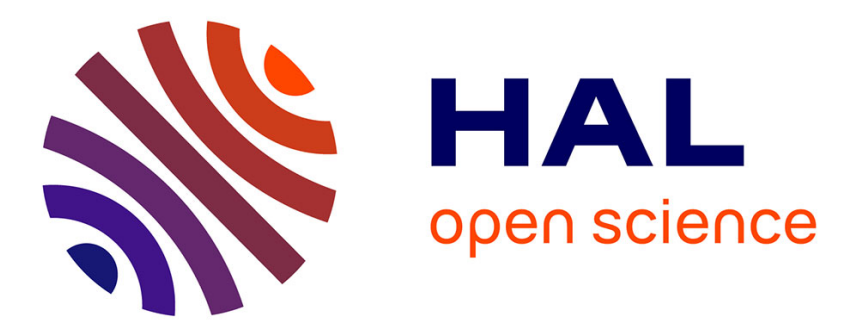

\title{
Operational experience of the computer control of an electrostatic generator
}

\author{
T.W. Aitken, C.W. Horrabin, W.T. Johnstone, K. Spurling
}

\section{To cite this version:}

T.W. Aitken, C.W. Horrabin, W.T. Johnstone, K. Spurling. Operational experience of the computer control of an electrostatic generator. Revue de Physique Appliquée, 1977, 12 (10), pp.1395-1397. 10.1051/rphysap:0197700120100139500 . jpa-00244331

\section{HAL Id: jpa-00244331 https://hal.science/jpa-00244331}

Submitted on 1 Jan 1977

HAL is a multi-disciplinary open access archive for the deposit and dissemination of scientific research documents, whether they are published or not. The documents may come from teaching and research institutions in France or abroad, or from public or private research centers.
L'archive ouverte pluridisciplinaire HAL, est destinée au dépôt et à la diffusion de documents scientifiques de niveau recherche, publiés ou non, émanant des établissements d'enseignement et de recherche français ou étrangers, des laboratoires publics ou privés. 


\title{
OPERATIONAL EXPERIENCE OF THE COMPUTER CONTROL OF AN ELECTROSTATIC GENERATOR
}

\author{
T. W. AITKEN, C. W. HORRABIN, W. T. JOHNSTONE and K. SPURLING \\ Daresbury Laboratory, Science Research Council, Daresbury, \\ Warrington WA4 4AD, England
}

\begin{abstract}
Résumé. - On décrit le prototype dy système de contrôle par ordinateur de la machine pilote de Daresbury et l'expérience acquise en fonctionnant avec ce système et en particulier on discute le logiciel utilisé.
\end{abstract}

Abstract. - The prototype computer control system for the Daresbury pilot machine is described and the operational experience gained with the system and its specially designed software is discussed.

1. Introduction. - The control system for the NSF tandem [1] involves the use of a number of small computers and control stations linked together by a serial data link. A diagram of the complete system is shown in the paper presented at this conference by Dr. R.G.P. Voss [2].

Many of the stations are housed inside the main pressure vessel and this presents a very severe shielding problem. Unless special precautions are taken it is very easy to destroy delicate electronic components in this type of environment. It was necessary to run a prototype system in as large a machine as possible to make sure that the methods of screening which had been developed would give satisfactory protection. It is the experience obtained of running this prototype system [3] in the pilot machine which is the subject of this paper.

2. The pilot machine system. - The pilot machine system consists of a ground station outside the machine and a data station in the high voltage terminal linked by two infra red light beams through the column. One beam transmits up to the terminal and the other transmits from the terminal down to ground. The crates which are used to house the electronics are doubled shielded as are the transmitter and receiver units. Figure 1 shows typical crates with their infra red transmitter and receiver units and figure 2 shows the pilot machine terminal with its data crate installed.

Data is sent over the link as a series of digital bit streams of the form shown in figure 3 , where the bit transmission rate is $2.5 \mathrm{Mbits} / \mathrm{s}$. The bit pattern is designed for a much larger system in which up to 64 crates each containing 256 addresses can be joined together. The pilot machine system uses only 2 crates and 18 addresses and these are used to set 8 analogue

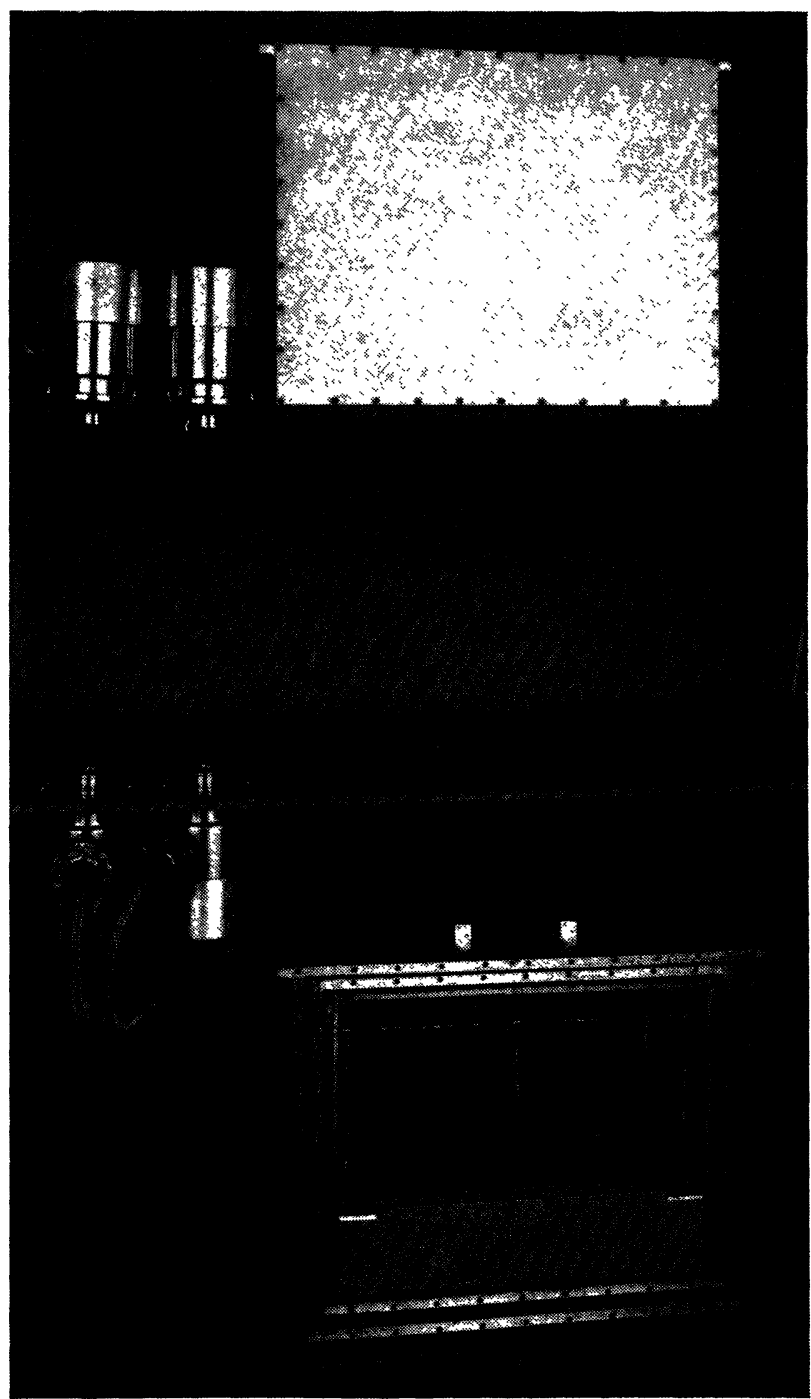

FIG. 1. - Data link crates, showing double shielding and the transmitter and receiver units. 


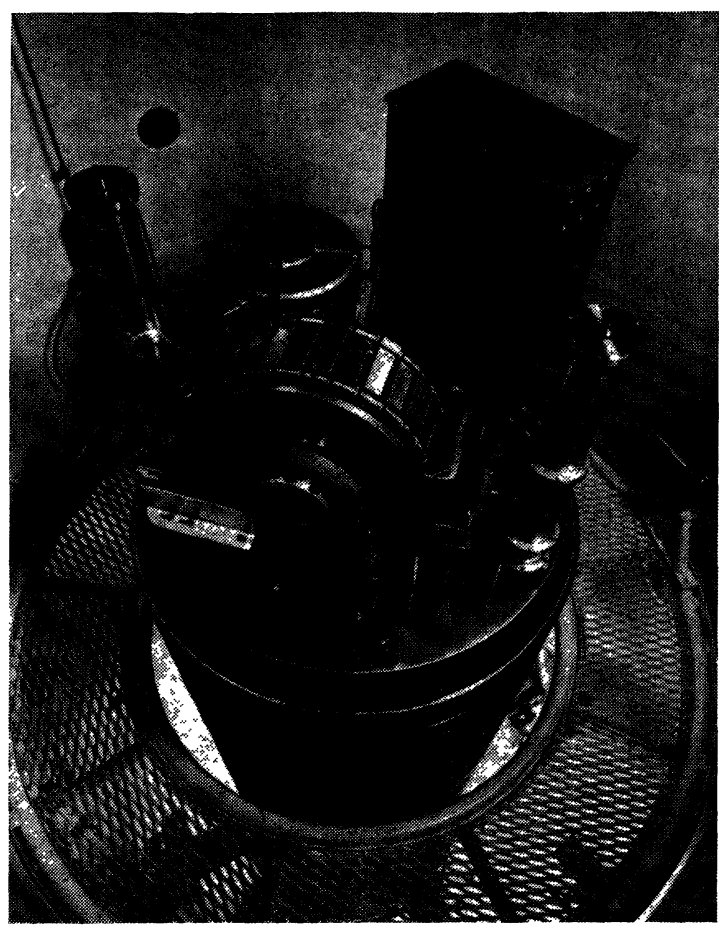

FIG. 2. - Pilot machine terminal showing the data crate in position.

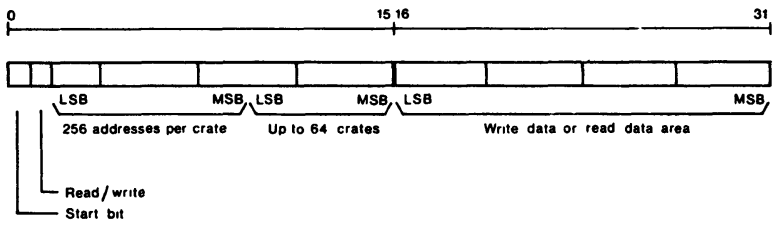

Simple serial message structure.

FIG. 3. - Digital bit stream.

and 16 digital output channels in the terminal crate controlling such things as EHT supplies and the 8 analogue and 16 digital input monitoring channels are used to measure voltages, currents, temperatures and vibration levels in the terminal which are of interest to the operator at ground level.

The ground station is shown in figure 4 . This sends data into and collects data from the link in response to instructions from an Interdata 7/16 mini computer attached to the link by CAMAC. The control and monitoring programs are scheduled by an operating system which supports, via CAMAC the plant data system, an interactive colour TV display, a badge reader, two floppy disc memory units and two incremental encoders for manual adjustment of parameters, as well as the typewriter keyboard.

The operator obtains access to the controls by entering his card in the badge reader. If he is recognised as an authorised operator he is then allowed to select various alternative modes of control by using the light pen and can adjust parameters as required. $\mathrm{He}$ is also able to alter single program constants or blocks of constants held in store using the typewriter. The colour TV display shows a mimic diagram of the

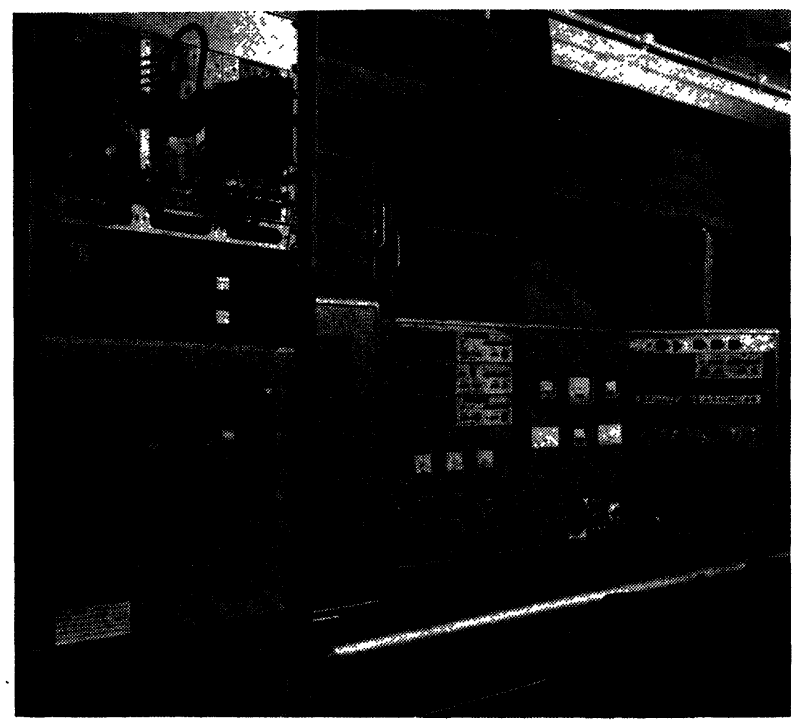

FIG. 4. - Control console and computer control rack.

elements being controlled and monitored. Figure 5 shows a typical charging system display in which, in addition to status information, a variety of numbers of interest are displayed such as supply voltages and charging and column currents in the appropriate units. These values are continuously updated on the screen at least once per second and in some cases 10 times per second where more rapid information is required. There are only two controls knobs available connected to digital encoders. These are assigned as required to the parameters to be varied using the light pen.

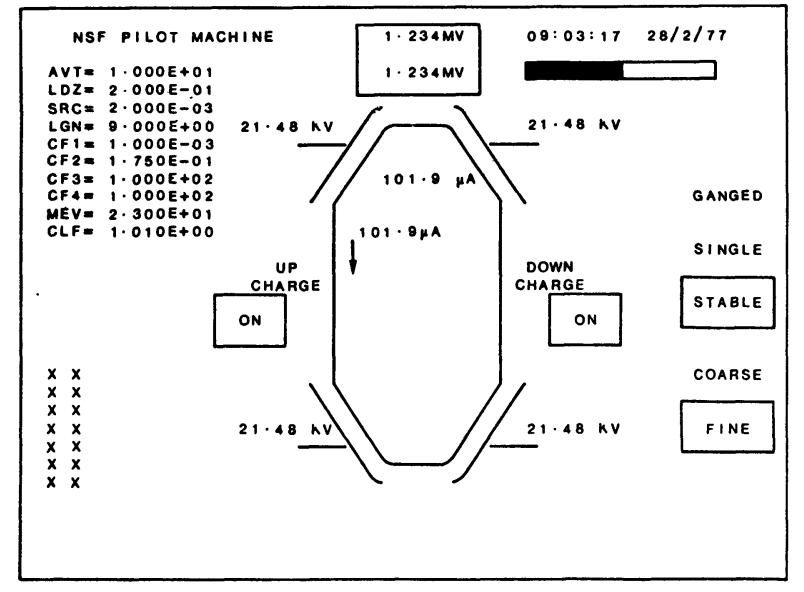

FIG. 5. - Colour display mimic diagram.

The first application of the computer control has been to the charging system. Three types of control can be selected. One mode gangs all four laddertron charging supplies together so that they all track precisely in response to one encoder. The program allows ratios to be set in between the supplies and individual gradients and offsets to be included to make the system track more accurately. The second mode separates the upcharge and downcharge supplies and 
provides control of these independently from the two encoders. This is analogous to tuning a quadrupole doublet or triplet where simultaneous control of the two parameters without continual switching is essential. The third mode gives the computer control of the charging electrodes in a servo loop, to keep the terminal voltage constant by controlling the charging current [4]. In this case the only control the operator needs is the voltage reference value and this is incremented using one of the encoders. The software for this mode is a highly sophisticated real time program which involves a second order digital filter to enable the frequency response of the loop to be optimised for the fastest possible stable response. A schematic diagram of the filter is shown in figure 6 . The full stabilization program is shown in figure 7 and figure 8 shows the open loop frequency response of the system including the digital filter to demonstrate the optimum response achieved. All the feedback parameters such as loop gain, corner frequencies and protection levels can be altered on line (provided the operator's card

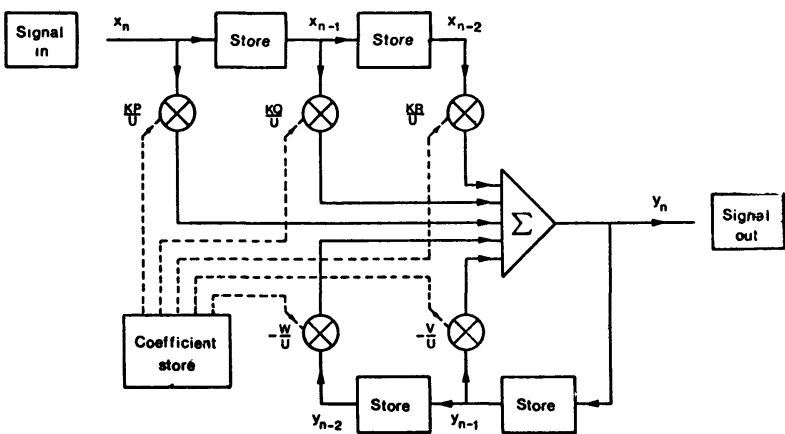

FIG. 6. - Schematic diagram of the digital second order filter.

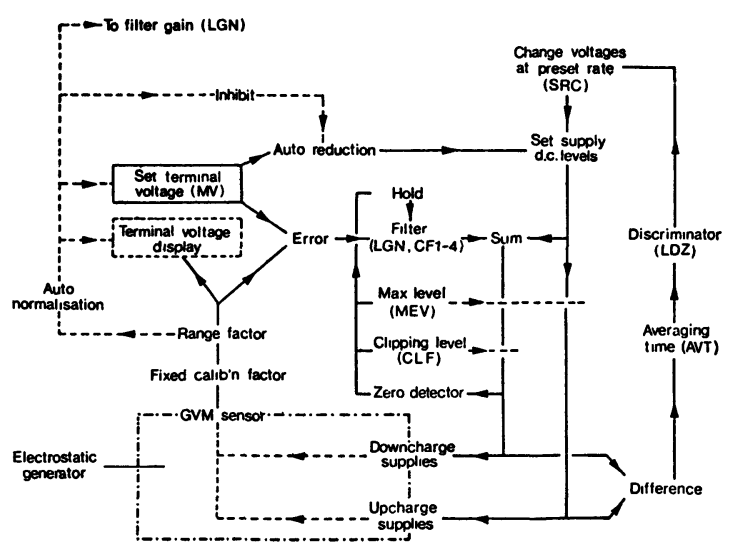

FIG. 7. - Schematic diagram of the full stabilization program.

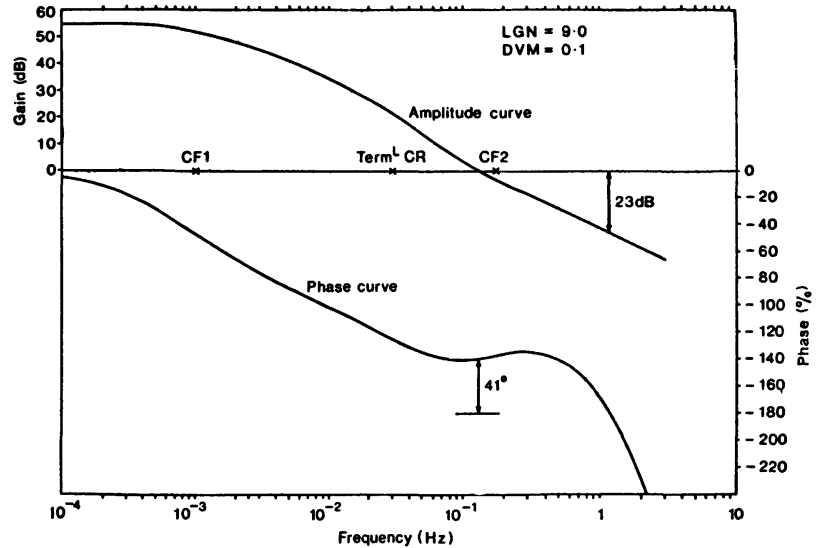

Fig. 8. - Open loop frequency response of the feedback system.

badge allows this) and the program includes facilities to prevent overcharging, to allow automatic voltage run up, to monitor the state of the loop and also special routines to enable the loop to be switched in and out without any transients.

3. Operational experience. - The terminal crate has now been in operation for over 2 years, the full computer controlled system for a year and the stabilization program for 6 months. It has proved an extremely stable and reliable system with both the hardware and software performing perfectly over this period. The stabilization program has been particularly successful and has been used to considerable effect in the accelerator tube tests carried out recently. Operator experience has been encouraging. The light pen is easy to use and the multiple use of the two controls soon becomes acceptable. A recent addition to the display has been a horizontal moving strip display of the servo error which gives an immediate assessment of the condition of the feedback loop, i.e. whether it is operating normally or having to correct strongly for machine loading. This has proved to be a very acceptable way of presenting this information.

4. Conclusion. - The $30 \mathrm{MV}$ machine will have a control system based on the experience gained with this prototype. Many of the display and software requirements are becoming clearer as more experience is gained with this system. It is clear that the degree of control and monitoring which this type of link provides is far superior to any of the alternative systems and that the flexibility of the ground control station opens up a wide range of control and monitoring possibilities to cover almost all requirements.
[1] Horrabin C. W., Johnstone W. T. and Spurling K., Daresbury Laboratory Report DL/NSF/R13 (1975).

[2] Voss R. G. P., The Nuclear Structure Facility at Daresbury Laboratory - presented at this conference.
[3] Horrabin C. W., Daresbury Laboratory Prepint DL/NSF/P49 (1977).

[4] Aitken T. W., Goodall I. and SpurLing K., Daresbury Laboratory Preprint DL/NSF/P50 (1977). 